\title{
Generalized pustular psoriasis in infant with heterozygous mutation in the IL36RN gene successfully treated with infliximab
}

\author{
Mia Glerup ${ }^{1 *}$, Jens Veirum ${ }^{1}$, Lars Iversen ${ }^{2}$, Mette Christiansen ${ }^{3}$, Troels Herlin ${ }^{1}$ \\ From 21st European Pediatric Rheumatology (PReS) Congress \\ Belgrade, Serbia. 17-21 September 2014
}

\begin{abstract}
Introduction
Homozygous missense mutation in the IL36RN gene resulting in deficiency of interleukin-36-receptor antagonist (DITRA) is phenotypically presented as severe generalized pustular psoriasis starting in early childhood. Compound heterozygous cases have been described with the same DITRA phenotype, but to our knowledge heterozygous IL36RN mutation related to severe generalized pustular psoriasis in early childhood has not been described.
\end{abstract}

\section{Objectives}

Case report

\section{Methods}

Case report

\section{Results}

First child of non-consanguineous caucasian (Danish) parents prenatally diagnosed with tetralogy of Fallot. Array CGH revealed normal karyotype. Pregnancy and delivery was uneventful. Mother had hemorrhagic proctitis and psoriasis. The girl presented at 3 months of age with what appeared as infectious dermatitis and $S$. aureus cultured from skin lesions spreading to extremities and trunk. Blood tests including acute phase reactants were normal. She started on intravenous antibiotics and topical corticosteroids. During the following week the dermal changes presented with scaly sharply demarcated psoriasiform plaques. Infection was cleared and topical betamethasone gave a partial improvement. Cardiac surgery was performed at the age of 4 months. Procedures were

${ }^{1}$ Pediatrics, Aarhus University Hospital, Skejby, Denmark Full list of author information is available at the end of the article uncomplicated but a precipitous flare of numerous pustules was then observed. Methotrexate treatment was initiated. On suspection for DIRA or DITRA genetic testing for IL1RN and IL36RN gene mutations was initiated. The girl was found to be heterozygous for a mutation in the IL36RN gene (exon 5, c 338C > T p Ser113Leu) whereas the ILIRN gene (mutated in DIRA patients) was normal. Additionally, a heterozygous mutation in the NLRP3 gene was also found (exon 3, c.2107C >A, p.Gln703Lys) via whole exome sequencing. Treatment with anakinra ( $4 \mathrm{mg} / \mathrm{kg} /$ day) had a marked positive effect, but did not result in total remission. MTX was increased to $15 \mathrm{mg} /$ $\mathrm{m}^{2} /$ week given subcutaneously. After 8 weeks and optimized doses $8 \mathrm{mg} / \mathrm{kg} /$ day of anakinra without sufficient remission the treatment was shifted to infliximab $6.5 \mathrm{mg} /$ $\mathrm{kg} /$ dose on Day $0,14,28$, hereafter every 4 weeks with excellent effect within few days on skin, general condition and thrive.

\section{Conclusion}

To the best of our knowledge we report the first detailed description of an infant with heterozygous S113L IL36Ra mutation along with heterozygous Q705K NLRP3 mutation, phenotypically expressed as DITRA with severe generalized pustular psoriasis. Reduction of the IL36Ra function will lead to excessive activity of cytokines belonging to the IL-1 family, furthermore the gain-of-function mutation in NLRP3 will lead to excessive IL-1b and IL-18 production. Collectively, it makes it conceivable that antiIL-1 treatment would exert an effect on the disease. Accordingly anakinra has previously been reported with a successful result for the treatment of DITRA (1). Also in our patient anakinra showed a marked effect on general condition, reduced the eruptions of pustular lesions, but the erythrodermal changes were preserved and therefore 
only a partial response of the skin lesions could be registered. However, we demonstrate in this infantile DITRA patient that TNF-alpha inhibition with infliximab dramatically improved the dermal changes and could normalize the skin within few weeks.

\section{Disclosure of interest}

None declared.

\section{Authors' details}

'Pediatrics, Aarhus University Hospital, Skejby, Denmark. ${ }^{2}$ Department of Dermatology, Aarhus University Hospital, Aarhus N, Denmark. ${ }^{3}$ Clinical Immunology, Aarhus University Hospital, Aarhus N, Denmark.

Published: 17 September 2014

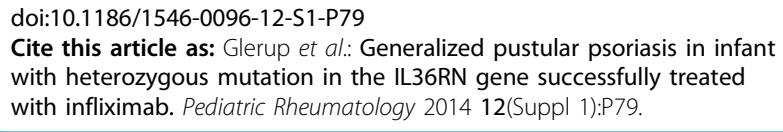

Submit your next manuscript to BioMed Central and take full advantage of:

- Convenient online submission

- Thorough peer review

- No space constraints or color figure charges

- Immediate publication on acceptance

- Inclusion in PubMed, CAS, Scopus and Google Scholar

- Research which is freely available for redistribution

Submit your manuscript at www.biomedcentral.com/submit 